\title{
EFECTO DE LA REFRIGERACIÓN SOBRE LA MOTILIDAD, INTEGRIDAD DE MEMBRANA ACROSOMAL Y REACCIÓN ACROSOMAL EN ESPERMATOZOIDES CANINOS ${ }^{1}$
}

\author{
Iris Manosalva P. ${ }^{2}$, Constanza Cortés ${ }^{3}$, Víctor Leyva V. ${ }^{4}$, Martha Valdivia C. ${ }^{2}$, \\ Mónica De los Reyes S. ${ }^{5}$, Claudio Barros R. ${ }^{3}$ y Ricardo Moreno M. ${ }^{3}$
}

\section{Abstract}

Preservation methods of spermatozoa using refrigeration have been developed for canine sperm; however, the rate of fertilization is still low, possibly due to cell damage for unknown reasons. The objective of this study was to evaluate the effect of refrigeration upon motility, mitochondrial activity, acrosomal membrane integrity, and acrosomal reaction in dog sperm incubated in three culture media (Ferp Talp, CCMm, Sp Talp) using new methodologies (Mito Tracker, Lyso Tracker, SBTI). The results indicated that exist a significant decrease $(\mathrm{p}<0.05)$ in motility, mitochondrial activity, and acrosomal membrane integrity in refrigerated sperm in comparison with fresh sperm. Also, the dynamic of acrosomal reaction was different in refrigerated sperm in comparison with fresh sperm. The Sp Talp and CCMm media showed the best results in holding the mitochondrial activity and acrosomal membrane integrity.

Key words: dog sperm, acrosome reaction, membrane integrity, mitochondrial activity, chilled sperm

\section{Resumen}

Métodos de preservación de espermatozoides mediante la refrigeración o el congelamiento han sido desarrollados para espermatozoides caninos; sin embargo, la tasa de fecundación artificial es baja, posiblemente por daños celulares aún no determinados. El objetivo de este estudio fue evaluar el efecto de la refrigeración sobre la motilidad, actividad mitocondrial, integridad de membrana acrosomal y reacción acrosomal

${ }^{1}$ Laboratorio de Reproducción de la Universidad de Chile y Unidad de Reproducción y Desarrollo de la Universidad Católica de Chile. Estudio financiado por el Programa Latinoamericano de Capacitación y Salud Reproductiva para América Latina y el Caribe (PROGRESAR-PLACIRH), Fondo Nacional de Desarrollo Científico y Tecnológico (FONDECYT-Chile).

${ }^{2}$ Laboratorio de Biología de la Reproducción Animal, Facultad de Ciencias Biológicas, Universidad Nacional Mayor de San Marcos

${ }^{3}$ Departamento de Ciencias Fisiológicas, Facultad de Ciencias Biológicas, Pontificia Universidad Católica de Chile

${ }^{4}$ Laboratorio de Reproducción, Facultad de Medicina Veterinaria, Universidad Nacional Mayor de San Marcos

${ }^{5}$ Laboratorio de Reproducción, Facultad de Ciencias Veterinarias y Pecuarias, Universidad de Chile 
en espermatozoides caninos incubados en tres medios distintos (Ferp Talp, CCMm, Sp Talp), utilizando nuevas metodologías (Mito Tracker, Lyso Tracker, SBTI). Los resultados indicaron una disminución significativa $(\mathrm{p}<0.05)$ en la motilidad, viabilidad e integridad del acrosoma en espermatozoides refrigerados en comparación con los frescos; así como una dinámica de reacción diferente en espermatozoides refrigerados respecto a los frescos. Por otra parte, los medios Sp Talp y CCMm dieron mejores resultados en mantenimiento de la motilidad, actividad mitocondrial e integridad de membrana acrosomal.

Palabras clave: espermatozoide canino, reacción acrosomal, integridad de membrana, actividad mitocondrial, semen refrigerado

\section{INTRODUCCIÓN}

El interés por mejorar la fecundación en canes se centra principalmente en el potencial económico que tienen estos animales. La necesidad de mejorar la propagación de la especie, preservar la línea germinal o aumentar la producción de crías en razas que tengan una baja tasa de fecundación, ha incentivado la investigación de nuevas tecnologías reproductivas. Un segundo ámbito de interés es que el perro podría ser un modelo de estudio en el laboratorio para mejorar la fecundidad o preservar gametos de especies en peligro de extinción, como el lobo ártico (Canis lupus), el lobo de etiopía (Canis simesis), el lobo mexicano (Canis lupus baileyi), o el zorro rosado de San Joaquín (Vulpes macrotis mutica).

Lo expuesto ha inducido a diseñar diversas metodologías que permiten extender y preservar la capacidad fecundante del semen canino. La refrigeración a $4{ }^{\circ} \mathrm{C}$ permite preservar el semen por algunas horas en tanto que la congelación podría preservar espermatozoides por muchos años. La tasa de preñez al utilizar semen refrigerado varía entre 45 y $65 \%$, y depende de factores como la calidad del semen, el momento de inseminación y el lugar donde se deposite el semen (útero o vagina) (Linde-Forsberg, 1995; Linde-Forsberg, 2001), mientras que la tasa de preñez con semen fresco es alrededor del 84\% (Linde-Forsberg y Forsberg, 1989, Linde-Forsberg, 2001). Esta diferencia podría deberse a que los espermatozoides pueden experimentar daños a nivel de la membrana plasmática y probablemente también a nivel del acrosoma durante el proceso mismo de la refrigeración.

El acrosoma es una vesícula de secreción que se encuentra en la cabeza del espermatozoide y contiene numerosas enzimas hidrolíticas. Este organelo tiende a romperse en el proceso de refrigeración y calentamiento teniendo por consecuencia que el espermatozoide pierde su capacidad fecundante (Peña y Linde-Forsberg, 2000).

Se ha observado en bovinos (Wheeler y Seidel, 1987), en humanos (Critser et al., 1987) y en ratones (Fuller y Whittinghan, 1987) que los espermatozoides sometidos a algún proceso de preservación en el tiempo, como la refrigeración y el congelamiento, penetran en los ovocitos en un tiempo menor (Watson, 1995). En el caso de espermatozoides caninos se evidencia un cambio en el tiempo para que ocurra la capacitación, probablemente debido también al proceso de refrigeración.

En el presente estudio se evaluó el efecto de la refrigeración sobre la motilidad, la actividad mitocondrial, la integridad de membrana acrosomal y la reacción acrosomal en espermatozoides caninos incubados en tres medios de cultivo utilizando las metodologías de Mito Tracker, Lyso Tracker y SBTI, a fin de esclarecer la funcionalidad del espermatozoide, el agente causante a nivel celular del 
efecto de la refrigeración y determinar un medio eficiente para ser utilizado en la fecundación in vitro.

\section{Materiales y Métodos}

\section{Lugar de estudio}

La colección y evaluación inicial del semen fresco se llevó a cabo en el Laboratorio de Reproducción Animal de la Facultad de Medicina Veterinaria de la Universidad de Chile. Los demás procedimientos se realizaron en la Unidad de Reproducción y Desarrollo de la Pontificia Universidad Católica de Chile.

\section{Diseño experimental}

Se utilizaron tres perros de 2 a 3 años de edad (Fox Terrier, Australian Terrier y Puddle Toy). Se realizaron 3 colectas de semen por perro, con una frecuencia no menor de una semana entre colectas por perro. El semen fue diluido en Buffer Tris 1:2, distribuido en 6 tubos de vidrio cónicos y centrifugados en forma inmediata a $700 \mathrm{G}$ por 5 minutos. Se descartó el sobrenadante.

Para el tratamiento del semen fresco, tres tubos de semen fueron suspendidos en uno de los tres medios de cultivo bajo evaluación. Se usó una concentración de $30 \times 10^{6}$ espermatozoides/ml (Rota et al., 1999) y se incubaron a $37{ }^{\circ} \mathrm{C}$ en una estufa de $\mathrm{CO}_{2}$. $\mathrm{La}$ evaluación se hizo a las 0,3 y 6 horas de incubación (Guérin et al., 1999).

Para el tratamiento del semen refrigerado, tres tubos de semen fueron resuspendidos en diluyente de refrigeración (concentración de $200 \times 10^{6}$ espermatozoides/ml (Rota et al., 1999), manteniéndose a $4{ }^{\circ} \mathrm{C}$ por 24 horas. Luego, el diluyente se eliminó por centrifugación a $200 \mathrm{G}$ x 1 minuto y el semen se resuspendió en los tres medios bajo evaluación, incubándose a $37{ }^{\circ} \mathrm{C}$ en una estufa de $\mathrm{CO}_{2}$. La evaluación se hizo a las 0,3 y 6 horas de incubación.
Se utilizaron tres medios de cultivos: Fert Talp (Parrish et al., 1988), CCMm (Guérin et al., 1999) y Sp Talp (Parrish et al., 1988). Los medios de cultivo, una vez preparados, fueron pasados por un filtro de $0.2 \mu \mathrm{M}$ Millipore y equilibrados por $2 \mathrm{~h}$ a $37^{\circ} \mathrm{C}$, con $95 \%$ de humedad y $5 \%$ de $\mathrm{CO}_{2}$, Buffer tris y dilutor yema de huevo tris-fructosa-tris (EYT) (Rota et al., 1995; Tsutsui et al., 2003).

\section{Evaluación de espermatozoides}

\section{Motilidad}

Se evaluó en forma subjetiva.

\section{Viabilidad}

Se determinó con dos sondas fluorescentes: el Mito Tracker (Mito Tracker Red CMXROS, Molecular Probes, Cat \# M7512) y el Lyso Tracker (Lyso Tracker Green DND-26, Molecular Probes, Cat \# L-7526).

\section{Actividad mitocondrial}

Se incubaron los espermatozoides con $2 \mathrm{nM}$ de Mito Tracker ${ }^{\mathrm{TM}}$ protegidas de la luz por 5 minutos a $37^{\circ} \mathrm{C}$ y con microscopía de epifluorescencia (Nikon Opriphot-2) y se contaron más de 100 espermatozoides en diferentes campos. La evaluación se hizo cada tres horas. Se consideró actividad mitocondrial positiva si los espermatozoides presentaban fluorescencia roja (Moreno y Barros, 2000).

\section{Integridad de la membrana acrosomal}

Se utilizó la sonda Lyso Tracker y el yoduro de propidio (Molecular Probes, Cat \# P3566) en concentración final de $2 \mu \mathrm{M}$ y $1 \mu \mathrm{M}$, respectivamente, en medio de cultivo con espermatozoides (Thundathil et al., 2001). Los espermatozoides fueron considerados como vivos y con el acrosoma intacto si tenían fluorescencia verde (Lyso Tracker) y muertos si tenían flourescencia roja (yoduro de propidio) (Thundathil et al., 2001). Se hizo 

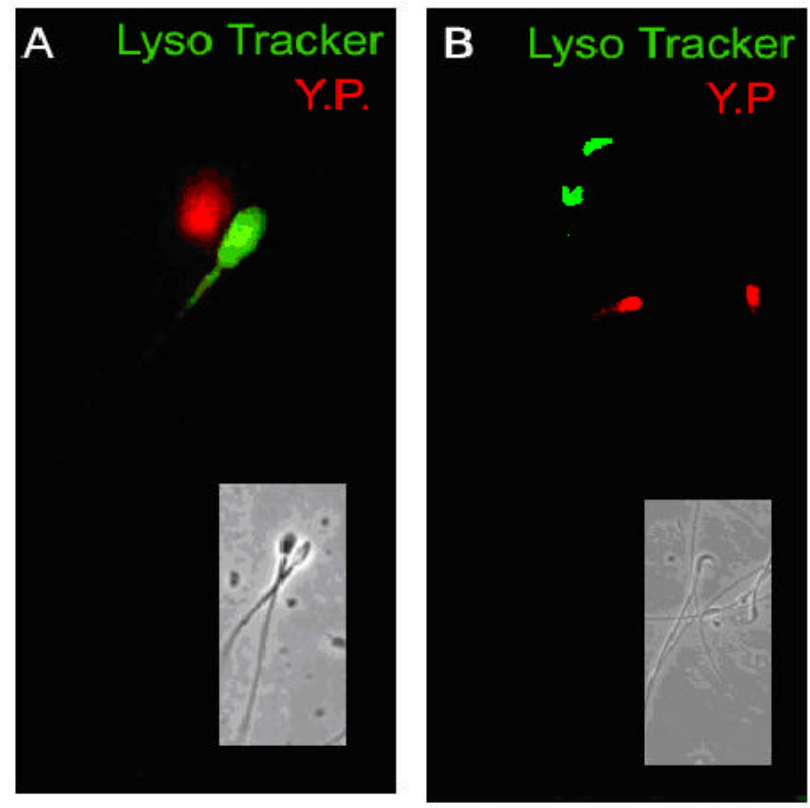

Figura 1. Marcación de espermatozoides caninos con Lyso Tracker y Yoduro de propidio (Y.P.). Espermatozoides caninos en A y de hámster en B (control). La coloración verde muestra la integridad de membrana acrosomal (esta marcación que es de tipo ácido trópica marca la cabeza del espermatozoides y la zona media donde se encuentran las mitocondrias). La coloración roja muestra la tinción con el Yoduro de propidio el cual marca DNA de espermatozoides dañados, de ahí que se presenta coloración en la zona de la cabeza.

una evaluación cada 3 horas y se utilizó espermatozoides de hámster como control.

\section{Reacción acrosomal}

Se utilizó la tinción con SBTI-Alexa488 (SBTI trypsin inhibitor from soybean, Alexa Fluor ${ }^{\circledR} 488$ conjugate, Molecular Probes, Cat \# T-23011) y anticuerpos antiacrosina (Anti mouse Green Alexa Fluor, Molecular Probes, Cat \# A- 21006) a fin de demostrar la eficiencia del SBTI como marcador de reacción acrosomal. Se usaron anticuerpos monoclonales humanos para acrosina humana por su homología con anticuerpos monoclonales de canino.

\section{Reacción del acrosoma con SBTI}

Se incubó SBTI-Alexa-488 en una concentración de $3 \mathrm{nM}$ con espermatozoides a $37^{\circ} \mathrm{C}$ por 15 minutos y protegido de la luz
(Tollner et al., 2000). Se contaron no menos de 100 espermatozoides a 400x con un microscopio de epiflorescencia, diferenciándose los espermatozoides fluorescentes y determinándose el porcentaje de ruptura acrosomal. Se hizo una evaluación cada 3 horas y se utilizaron espermatozoides de hámster como control.

Reacción del acrosoma con anticuerpos monoclonales

Se utilizó la técnica de inmunoflorescencia indirecta (Moreno et al., 1998). Las muestras se observaron a 400x con un microscopio de epiflorescencia (Nikon Opthiphot-2). Se utilizaron espermatozoides humanos como control.

\section{Detección de la acrosina por Western Blott}

Se realizó el Western Blot para reconocer la especificidad de los anticuerpos. La 
forma molecular de acrosina fue analizada por unidimensional SDA-PAGE (Moreno et al, 2000). Se utilizaron extractos ácidos de espermatozoides humanos como control.

\section{Análisis estadístico}

Se utilizó la prueba de t-Student para evaluar espermatozoides frescos y refrigerados, y el análisis de varianza para medir las diferencias entre los tres medios de cultivo (Fert Talp, Sp Talp y CCMm) y entre los tres tiempos evaluados ( 0,3 y 6 horas).

\section{Resultados}

\section{Localización de Mito Tracker, Lyso Tracker y SBTI-Alexa 488 en esperma- tozoides caninos}

La sonda Lyso Tracker se localizó preferentemente en la región acrosomal y mitocondrial al igual que en los espermatozoides de hámster (Fig. 1). La sonda marcó únicamente a espermatozoides vivos y el yoduro de propidio marcó a los muertos. El SBTI-Alexa488 y los anticuerpos antiacrosina marcaron selectivamente el acrosoma en espermatozoides de perro (Fig. 2a y 3a) y de humano (Fig. 3b). Por otra parte, la sonda mitocondrial Mito Tracker se localizó en la pieza media del espermatozoide, que es la región donde se localizan las mitocondrias en la cola al igual que en espermatozoides de hámster (Fig. 4). La marca de acrosina es específica debido a que los anticuerpos utilizados fueron capaces de reconocer a esta enzima por Western Blot (Fig. 5). Los resultados muestran que los anticuerpos reconocieron una banda de $51 \mathrm{KDa}$ perteneciente a la proacrosina (en humanos 55/53 KDa), una banda de $45 \mathrm{KDa}$ perteneciente a $\propto$-acrosina (en humanos 49 $\mathrm{KDa}$ ) y una banda de $39 \mathrm{KDa}$ perteneciente a la $ß$-acrosina (en humanos $35 \mathrm{KDa}$ ).
Efecto de la refrigeración sobre la motilidad, actividad mitocondrial, integridad de membrana acrosomal y reacción acrosomal

La motilidad total $(73.0 \pm 7.0$ y $82.4 \pm$ 7.0) y la motilidad progresiva $(66.5 \pm 10.0 \mathrm{y}$ $80.7 \pm 7.0$ ) fueron significativamente menores en espermatozoides refrigerados que en frescos $(\mathrm{p}<0.05)$. El porcentaje de actividad mitocondrial fue significativamente menor en los refrigerados $(77.5 \pm 5.0$ y $85.6 \pm 7.0)$. Así mismo, el porcentaje de espermatozoides con integridad de membrana acrosomal fue significativamente menor $(77.0 \pm 5.0$ y 84.0 $\pm 7.0)$ y la reacción acrosomal fue mayor con SBTI $(17.0 \pm 4.0$ y $13.0 \pm 2.0)$ en los espermatozoides refrigerados que en los fres$\cos$ (Fig. 6, p<0.05).

Efecto de la refrigeración sobre los cambios en el tiempo de la motilidad en medios de cultivo

No se observó diferencia significativa en motilidad total ni en motilidad progresiva entre los distintos medios de cultivo a las $0 \mathrm{~h}$ (Fig. 7); sin embargo, en la evaluación de las $3 \mathrm{~h}$ se pudo observar que la motilidad de los espermatozoides frescos y refrigerados en el medio Fert Talp fue significativamente menor en comparación con Sp Talp y CCMm $(p<0.05)$, no habiendo diferencias entre estos últimos. A las $6 \mathrm{~h}$ de incubación se incrementó la diferencia entre el medio Fert Talp con el CMMm, tanto para los espermatozoides frescos como para los refrigerados. También se observó que la motilidad total, así como la progresiva fueron significativamente mayores $(\mathrm{p}<0.05)$ en los espermatozoides incubados con el medio CCMm (Fig. 8).

Efecto de la refrigeración sobre los cambios en el tiempo de la actividad mitocondrial en medios de cultivo

Se encontró diferencia significativa $(\mathrm{p}<0.05)$ en el porcentaje de actividad 

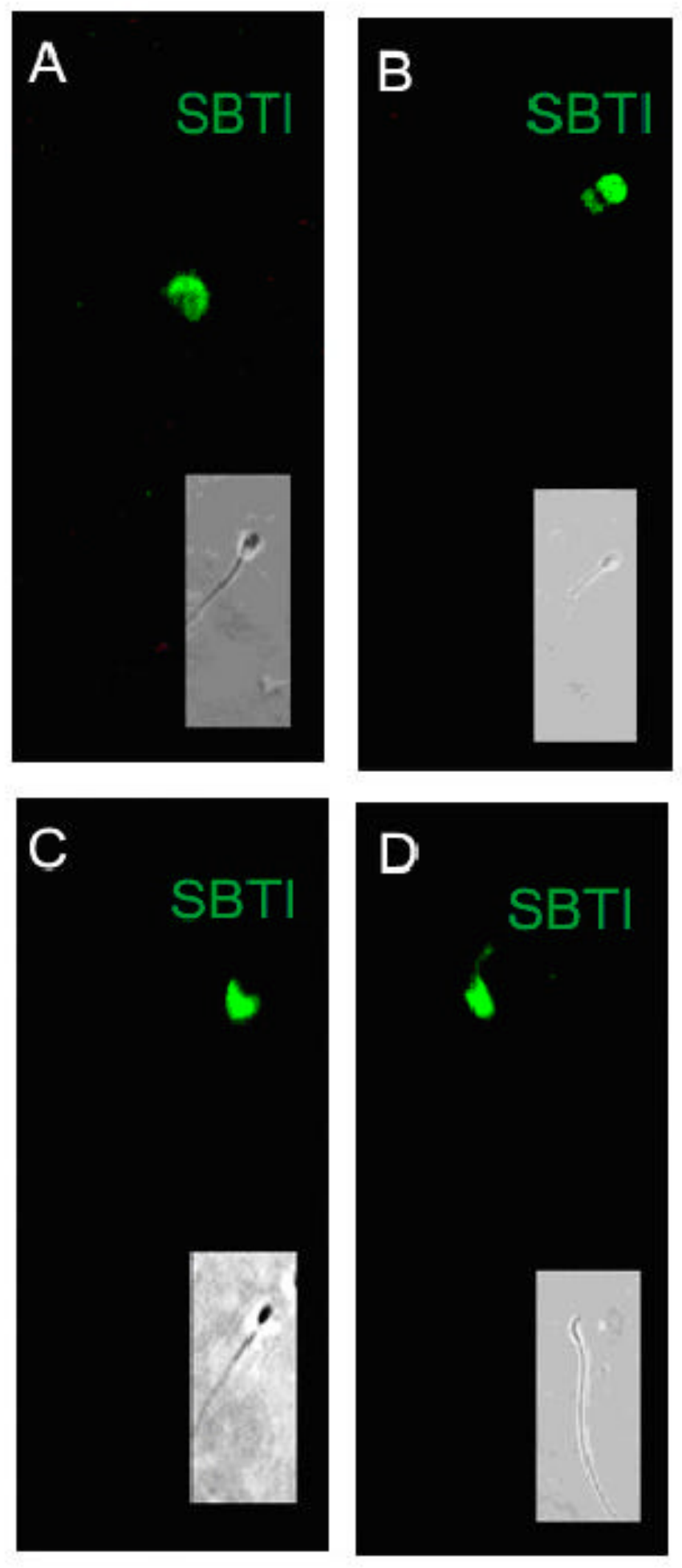

Figura 2. Marcación de espermatozoides caninos con SBTI. Espermatozoides caninos en A-C y espermatozoides de hámster (control) en D. En espermatozoides caninos se observan 3 criterios de tinción de acuerdo al estado de reacción acrosomal: espermatozoides con acrosoma reaccionado cuando presentan la marcación en la región del acrosoma (A), marcación en el acrosoma y parte en la región postacrosomal (B), y marcación en la región postacrosomal $(\mathrm{C})$. 

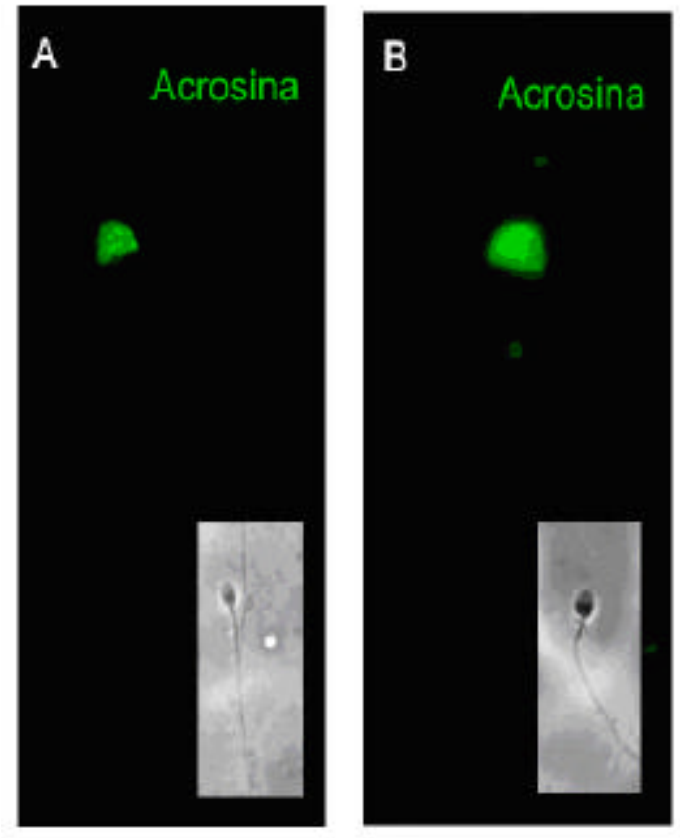

Figura 3. Inmunolocalización del anticuerpo monoclonal antiacrosina humana en espermatozoides caninos. Espermatozoides caninos en A y espermatozoides humanos (control) en B. Se observa claramente que la ubicación de la acrosina en espermatozoides caninos es similar a la localizada en espermatozoides humanos.
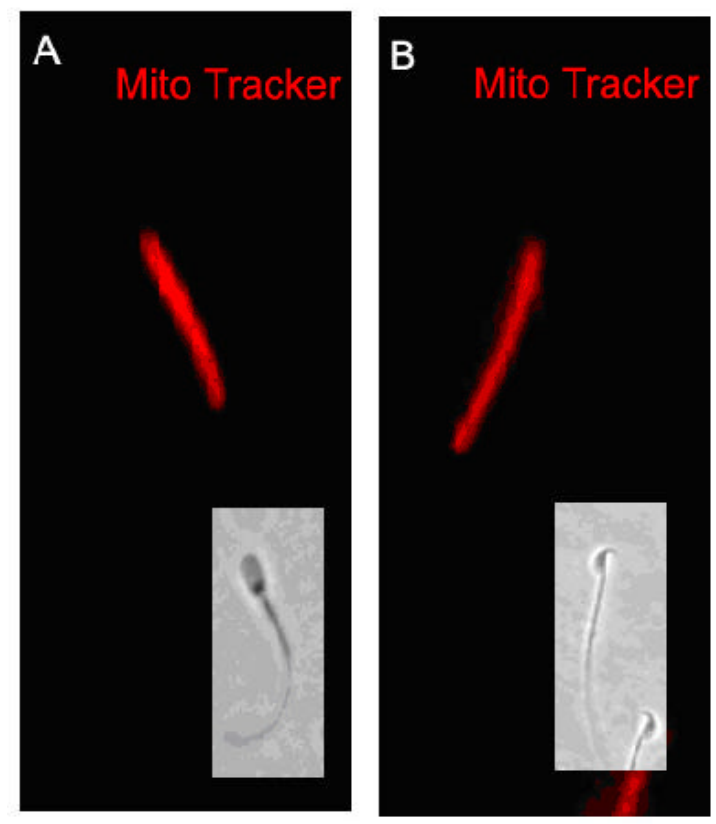

Figura 4. Marcación de espermatozoides caninos con Mito Tracker. Espermatozoides caninos en A y de hámster en $\mathrm{B}$ (control). La coloración fluorescente roja está asociada con la pieza media donde las mitocondrias están localizadas indicando el potencial de membrana mitocondrial. 


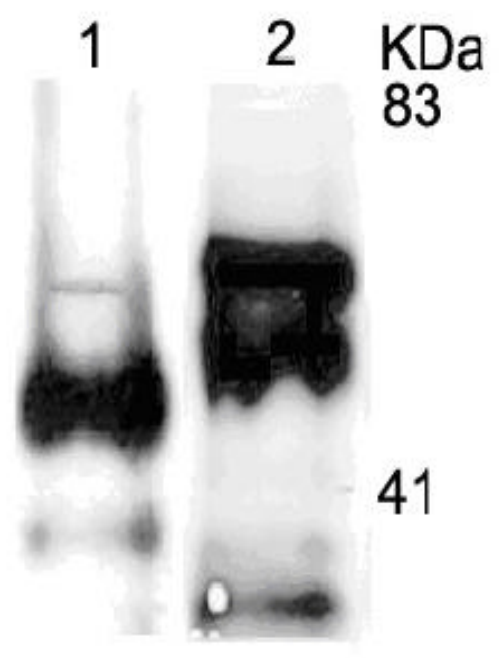

Figura 5. Identificación de acrosina en espermatozoides caninos por Western Blot. Acrosina en extractos proteicos caninos fue detectada usando una mezcla de anticuerpo monoclonal acrosina humana $\left(\mathrm{C}_{5} \mathrm{~F}_{10}, \mathrm{G}_{4} \mathrm{C}_{11}, \mathrm{~A}_{8} \mathrm{C}_{10}\right)$ en el carril 1. Extractos proteicos de espermatozoides humanos fueron usados como control. La acrosina encontrada tiene similar peso molecular en ambas especies con una ligera variación en espermatozoides caninos. Cada carril contiene $5 \mu \mathrm{g}$ de extractos proteicos y los pesos moleculares representan los marcadores de peso molecular.

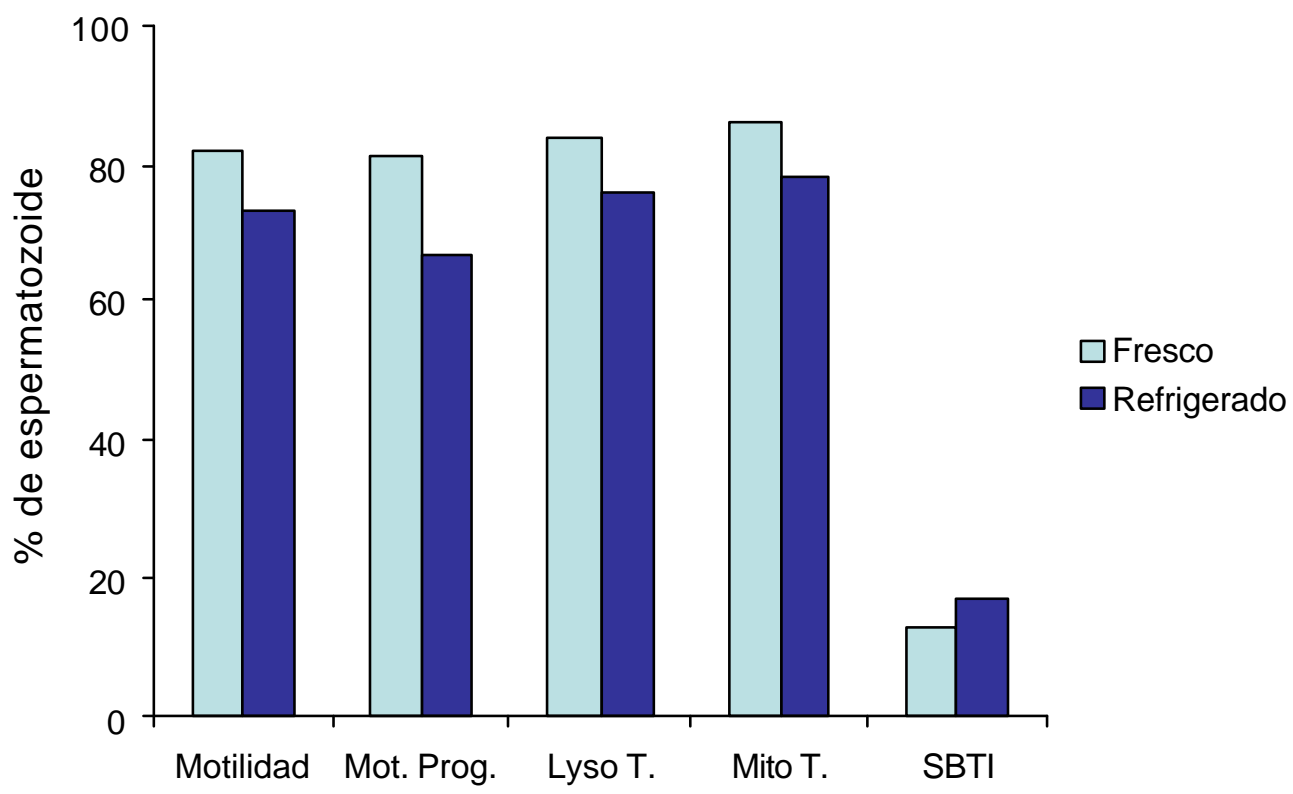

Figura 6. Efecto de la refrigeración en espermatozoides caninos $(p<0.05)$ sobre la motilidad, motilidad progresiva, integridad de la membrana acrosomal (Lyso Tracker), actividad mitocondrial (Mito Tracker) y aumento de la reacción acrosomal (SBTI) 
Espermatozoides frescos

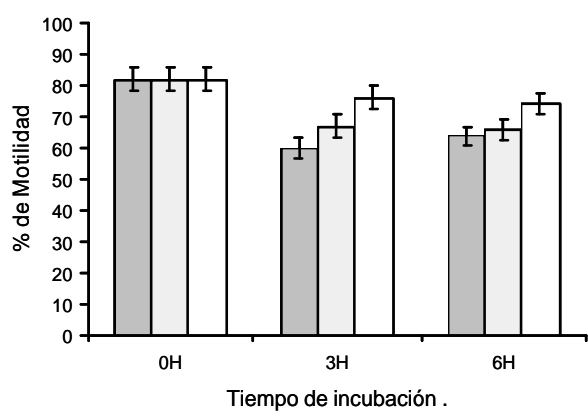

Espermatozoides refrigerados

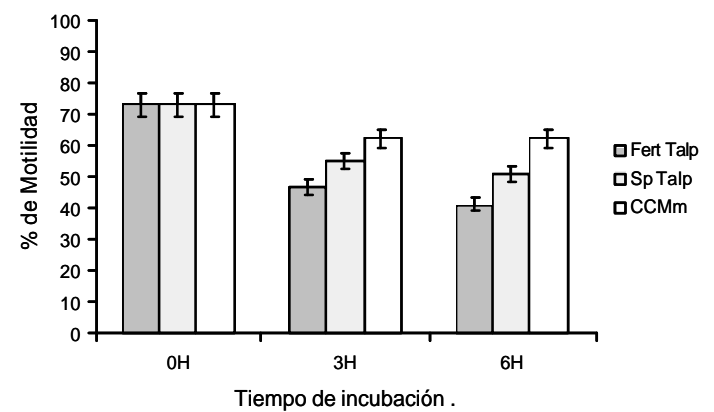

Figura 7. Efecto de la refrigeración sobre la motilidad de espermatozoides caninos en los medios Fert Talp, Sp Talp y CCMm

Espermatozoides frescos

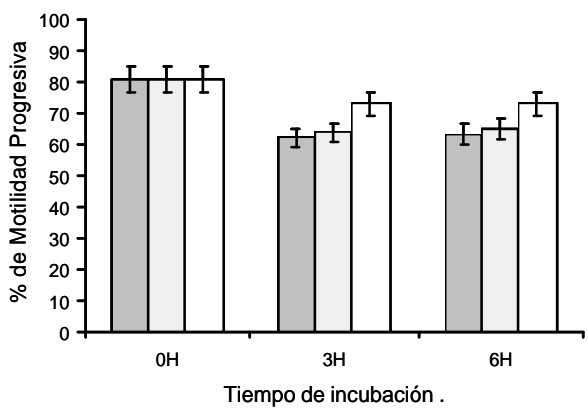

Espermatozoides refrigerados

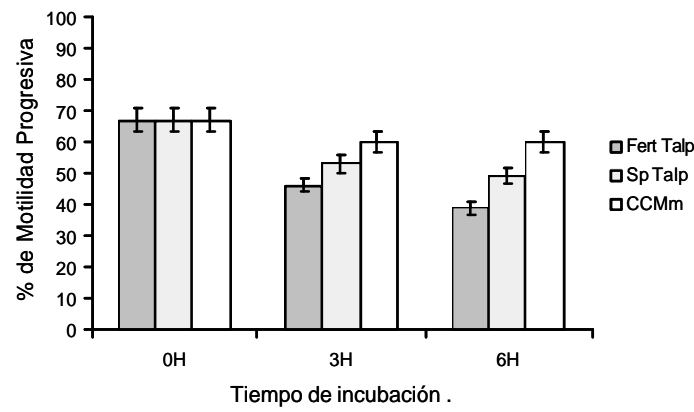

Figura 8. Efecto de la refrigeración sobre la motilidad progresiva de espermatozoides caninos en los medios Fert Talp, Sp Talp y CCMm

Espermatozoides frescos

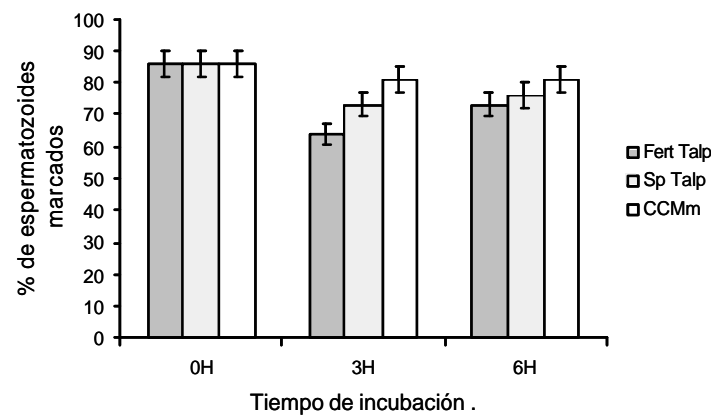

Espermatozoides refrigerados

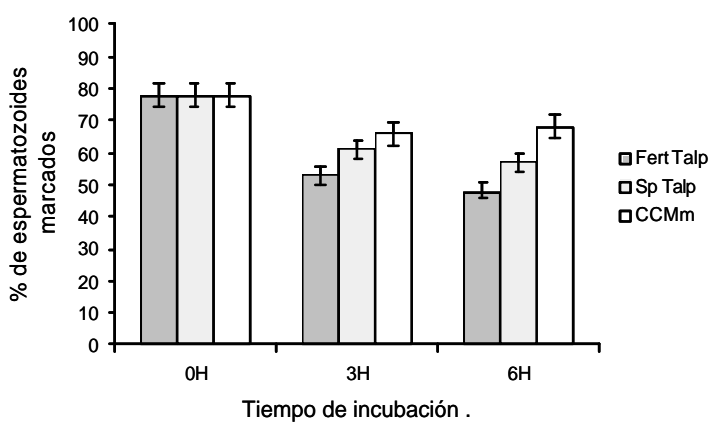

Figura 9. Efecto de la refrigeración sobre la actividad mitocondrial de espermatozoides caninos en los medios Fert Talp, Sp Talp y CCMm 

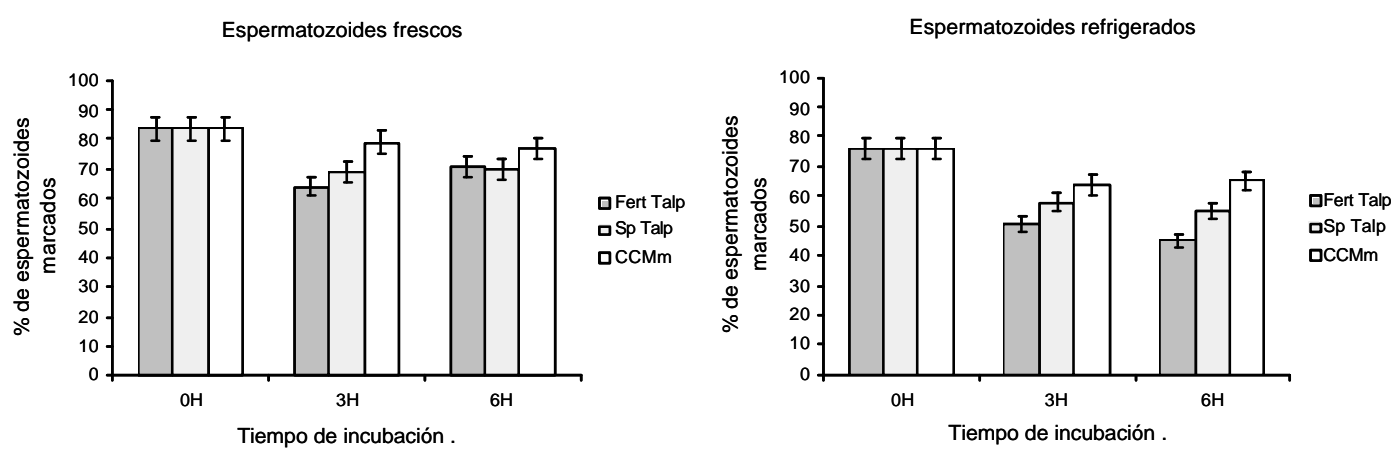

Figura 10. Efecto de la refrigeración sobre la integridad de la membrana acrosomal de espermatozoides caninos en los medios Fert Talp, Sp Talp y CCMm
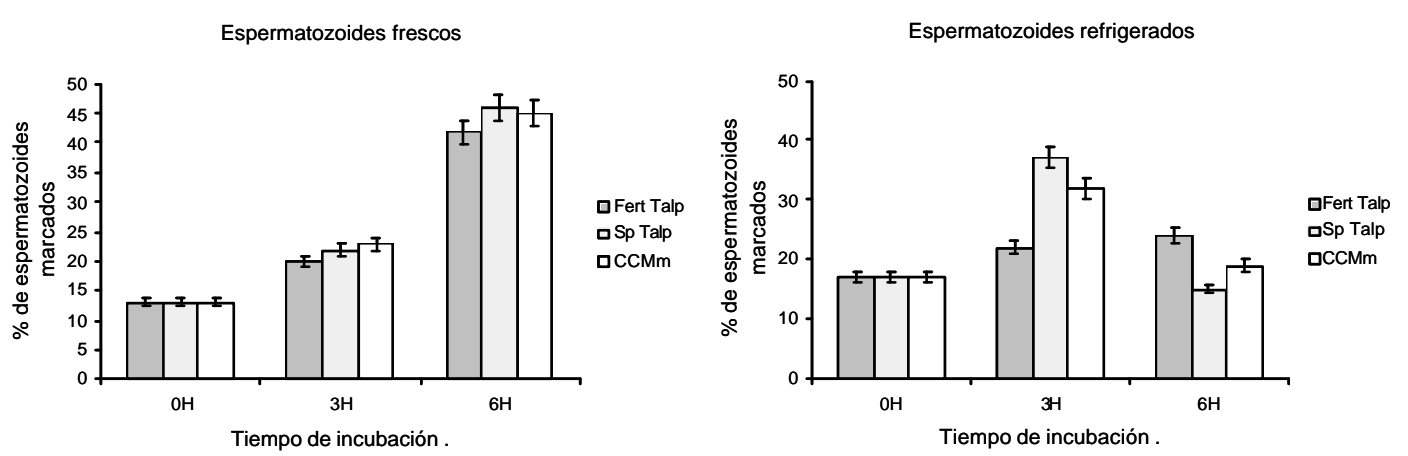

Figura 11. Efecto de la refrigeración sobre la reacción acrosomal con SBTI de espermatozoides caninos en los medios Fert Talp, Sp Talp y CCMm

mitocondrial de los espermatozoides frescos y refrigerados en los medios Fert Talp y CCMm a las 3 y 6 h de incubación (Fig. 9). Además, la disminución de la actividad mitocondrial entre las 0 y $3 \mathrm{~h}$ de incubación fue significativa $(\mathrm{p}<0.05)$ en los medios Fert Talp y Sp Talp en espermatozoides frescos y en los tres medios en espermatozoides refrigerados (Fig. 9).

Efecto de la refrigeración sobre los cambios en el tiempo de la integridad de la membrana acrosomal en medios de cultivo

Se observó una diferencia significativa $(p<0.05)$ en el porcentaje de integridad de membrana acrosomal en espermatozoides frescos y refrigerados que fueron incubados por 3 y $6 \mathrm{~h}$ en los medios Fert Talp y CCMm
(Fig.10). Por otro lado, se observó una disminución significativa $(\mathrm{p}<0.05)$ de integridad de membrana acrosomal entre las 0 y $3 \mathrm{~h}$ en los medios Fert Talp y Sp Talp en espermatozoides frescos y en todos los medios de cultivo en espermatozoides refrigerados; sin embargo, las diferencias encontradas entre las 3 y $6 \mathrm{~h}$ de incubación no fueron estadísticamente importantes.

Efecto de la refrigeración sobre los cambios en el tiempo de la reacción acrosomal en medios de cultivo.

\section{Análisis de la reacción acrosomal con SBTI}

Se observó un aumento significativo $(p<0.05)$ en el porcentaje de espermatozoides, 
frescos y refrigerados marcados con SBTIAlexa488 e incubados por $3 \mathrm{~h}$ en medio $\mathrm{Sp}$ Talp y CCMm (Fig. 11). Este aumento fue mayor a las $6 \mathrm{~h}$ de incubación en espermatozoides frescos pero el porcentaje de espermatozoides refrigerados marcados disminuyó significativamente $(\mathrm{p}<0.05)$ a las $6 \mathrm{~h}$ de incubación. Por otro lado, no se observaron cambios en el tiempo de reacción acrosomal en espermatozoides incubados en Fert Talp.

Análisis de la reacción acrosomal con anticuerpo monoclonal antiacrosina

El porcentaje de espermatozoides frescos marcados con antiacrosina fue significativamente mayor a las $6 \mathrm{~h}(\mathrm{p}<0.05)$. En cambio, la mayor respuesta con espermatozoides refrigerados se obtuvo a las $3 \mathrm{~h}$ de incubación, resultado similar al obtenido con la sonda SBTI.

\section{Discusión}

La motilidad permite predecir la capacidad fecundante in vitro de los espermatozoides (Donnelly et al., 1998). En el presente estudio, los resultados indicaron que la motilidad de los espermatozoides refrigerados disminuyó en $27 \%$ en comparación con los espermatozoides frescos, en forma similar a otros reportes (Rota et al., 1999; Tsutsui et al., 2003). El mecanismo por el cual disminuye la motilidad no ha sido elucidado por completo; sin embargo, se sabe que la motilidad espermática es particularmente dependiente de la función mitocondrial (Kao et al., 1998). Las mitocondrias se encuentran estratégicamente distribuidas alrededor de la pieza media del espermatozoide para proveer energía a la dineína que propulsa a los microtúbulos. Las mitocondrias son la mayor fuente de energía oxidativa a través de la producción de ATP vía la cadena transportadora de electrones (ECT).
La pérdida significativa de la motilidad encontrada en este estudio es diferente al reporte de $17 \%$ al cabo de 2 días utilizando un dilutor a base de yema de huevo y Tris fructosa citrato (EYT-FC) (Tsutsui et al., 2003), posiblemente debido al efecto de la centrifugación de los espermatozoides que se tiene que realizar para la incubación in vitro en los medios de cultivos que simulan al tracto genital canino de la hembra.

La actividad mitocondrial se afectó de la misma manera que la motilidad, indicando que la refrigeración afectaría inicialmente la membrana mitocondrial, y esto causaría la disminución de la motilidad (Vetter et al., 1998).

La sonda ácido trópica Lyso Tracker, al estar unida con un fluorocromo, puede producir fluorescencia en organelos de $\mathrm{pH}$ ácido. Se sabe que esta fluorescencia ocurre en algunos tipos celulares en contacto con los lisosomas (Haller et al., 1996) y en el caso de espermatozoides se tiñe el aparato de Golgi cuando se encuentran en la fase de espermátides (Moreno et al., 2000). En el caso de espermatozoides, se puede usar para evaluar el estado de la integridad de membrana acrosomal (Thomas et al., 1997).

El SBTI es un agente inhibidor de enzimas tipo tripsina, que actúa inhibiendo a la acrosina de espermatozoides humanos (Leyton et al., 1986), ratones (Benau y Storey, 1988), camarón de mar (Ríos y Barros, 1997) y pez estrella (Sousa et al., 1992). Para detectar el estado de reacción acrosomal se le utiliza en asociación con ALEXA Fluor en espermatozoides de monos (Tollner et al., 2000) y en asociación con biotina en espermatozoides humanos (Arts et al., 1994). Los resultados de reacción acrosomal del presente estudio, usando espermatozoides frescos en el medio CCMm a las 3 y $6 \mathrm{~h}$, fueron muy similares a los obtenidos con el uso del Spermac ${ }^{\circledR}$, el cual es uno de los mejores indicadores de reacción acrosomal (Guérin et al., 1999), de allí que el uso del SBTI pueda 
ser considerado de gran utilidad para la evaluación de espermatozoides caninos.

El mayor porcentaje de reacción acrosomal se observó a las 6 h de incubación en espermatozoides frescos, en tanto que la mayor parte de reacciones acrosomales ocurrió a las $3 \mathrm{~h}$ en espermatozoides refrigerados, en concordancia con otros estudios en caninos (Rota et al., 1999) y ratones (Fuller y Whittingham, 1997). Este resultado podría ser explicado por una desestabilización a nivel de la membrana, producto del refrigeramiento, en donde la composición lipídica de la bicapa se ve afectada por la tasa de refrigeración, lo cual causaría que el calcio se encuentre más permeable y por tanto entraría al espermatozoide iniciando la capacitación y en consecuencia la reacción acrosomal. Este proceso ha sido determinado previamente en espermatozoides de ovino a temperatura inferior de $15^{\circ} \mathrm{C}$ (Maxwell y Jonson, 1999). Por otro lado el efecto de la eliminación del plasma seminal por centrifugación y la dilución de los espermatozoides podría causar desestabilización de la membrana espermática (Huo et al., 2002).

A pesar que los espermatozoides capacitados resultantes de este proceso son capaces de fecundar in vitro o in vivo, estos tienen menor tiempo de vida (Maxwell y Johnson, 1999). A fin de utilizar espermatozoides capacitados durante el proceso de refrigeración para la fecundación in vitro se utilizó el medio Fert Talp que es usado para la fertilización in vitro de espermatozoides bovinos (Parrish et al., 1988). Sin embargo, este medio no fue el más conveniente para la coincubación de espermatozoides caninos con ovocitos debido a la rápida pérdida de viabilidad de los espermatozoides en este medio. No obstante, el conocimiento del tiempo de capacitación de espermatozoides caninos luego de un proceso de refrigeración podrá servir para determinar el tiempo óptimo para realizar pruebas de fecundación in vitro. Por otro lado, el hecho que en esperma-tozoides frescos no se haya encontrado diferencias de reacción entre medios de cultivo, a diferencia de espermatozoides refrigerados, podría deberse a los componentes de los medios de cultivo que estarían afectando a los espermatozoides refrigerados, ya que estos poseen membranas no intactas.

La diferencia de los resultados obtenidos con el uso de anticuerpos monoclonales para acrosina y SBTI podría deberse a que este último marca todas las enzimas acrosomales tipo tripsina, donde la acrosina estaría incluida, en tanto que los anticuerpos antiacrosina sólo detectan los formas moleculares de esta enzima en el acrosoma.

Los tres medios de cultivo bajo evaluación se seleccionaron por sus propiedades sobre los espermatozoides. Diversos trabajos indican que con el Sp Talp se obtienen mayores índices de capacitación que con otros medios, en parte debido a la presencia de $\mathrm{Ca}$ que induce la reacción acrosomal (Sirivaidyapong et al., 2000). Entre estos, el CCMm, modificación del medio de cultivo $\mathrm{CCMm}$, donde se ha reemplazado el bicarbonato de sodio, que tiene efectos nocivos sobre la motilidad espermática en semen canino, por el Tris para mantener la motilidad por más tiempo (Guérin et al., 1999), y el Fert Talp, usado para la fertilización in vitro de espermatozoides bovinos (Parrish et al., 1988). Los resultados muestran que el medio de cultivo que presentó mejores porcentajes de motilidad, integridad de membrana acrosomal y actividad mitocondrial en el tiempo fue el CCMm, pese a que no hubo diferencia estadística significativa con el Sp Talp.

En base a los resultados se podría sugerir que la motilidad, viabilidad, integridad de membrana acrosomal y reacción del acrosoma son afectados por la refrigeración. Esto sería una indicación que la vulnerabilidad de la membrana acrosomal y de la membrana mitocondrial ocasionaría la disminución de la motilidad espermática. El hallazgo de valores mayores de integridad mitocondrial que de motilidad podría sugerir que la muerte celular se realiza por apoptosis (Dinsdate $e t$ 
al., 1998; Green y Reed, 1998; Sun et al., 1999). Otros autores han señalado que este estado mitocondrial podría ser debido a alteraciones en el metabolismo de energía sin daño de integridad de membrana (Vetter $e t$ al., 1998); sin embargo, los resultados del presente estudio permiten postular que el efecto de la refrigeración es a nivel de integridad de membrana mitocondrial debido a la disminución de la integridad de membrana acrosomal.

\section{Conclusiones}

- El Lyso Tracker y el Mito Tracker permiten evidenciar índices de viabilidad espermática y el SBTI permite obtener índices de reacción acrosomal en tiempo real en espermatozoides caninos.

- El efecto de la refrigeración sobre los espermatozoides caninos se ve reflejado en la disminución de la motilidad, integridad de membrana y actividad mitocondrial y en el aumento de la reacción acrosomal.

- La dinámica de la motilidad, integridad de membrana acrosomal y actividad mitocondrial es similar en espermatozoides refrigerados y frescos.

- La cinética de la reacción acrosomal en espermatozoides refrigerados ocurre en un tiempo previo con respecto a espermatozoides frescos.

- Los medios de cultivo que producen menor pérdida de motilidad, integridad de membrana acrosomal y actividad mitocondrial son el CCMm y el Sp Talp, en comparación con el Fert Talp.

\section{Agradecimientos}

Los autores agradecen al Dr. Néstor Falcón por su invalorable ayuda y apoyo con el análisis estadístico de los datos del presente trabajo.

\section{LITERATURA CITADA}

1. Arts, E.; J. Keuiken; S. Jager. 1994. A new method to detect acrosomereacted spermatozoa using biotinylated soybean inhibitor. Fertil. Steril. 62: 10441055.

2. Benau, D; B. Storey. 1988. Relationship between two types of mouse sperm surface sites that mediate binding of sperm to the zona pellucida. Biol. Reprod. 39: 235-244.

3. Critser, J.; B. Arneson; D. Aaker; A. Huse-Benda; G. Ball. 1987. Cryopreservation of human spermatozoa. II. Post-thaw chronology of motility and of zona-free hamster ova penetration. Fertil. Steril. 47: 980-984.

4. Dinsdate, D.; J. Zhuang; G. Cohen. 1998. Redistribution of cytochrome precedes the caspase-dependent formation of ultracondensed mitochondria with a reduced inner membrane potential, in apoptotic monocytes. Am. J. Pathol. 155: 607-618.

5. Donnelly, E.; S. Lewis; I. McNally; W. Thompson. 1998. In vitro fertilization and pregnancy rates: the influence of sperm motility and morphology on IVF outcome. Fertil. Steril. 70: 305-314.

6. Fuller, S.; D. Whittingham. 1997. Capacitation-like changes occur in mouse spermatozoa cooled to low temperatures. Mol. Reprod. Dev. 46: 318-324.

7. Green, D.; D. Reed. 1998. Mitochondria and apoptosis. Science 281: 1309-1312.

8. Guérin, P.; M. Ferrer; A. Fontbonne; L. Bénigni; M. Jacquet; Y. Ménézo. 1999. In vitro capacitation of dog spermatozoa as assessed by chlortetracycline staining. Theriogenology 52: 617-628.

9. Haller, T.; P. Dieta; P. Deetjen; H. Volkl. 1996. The lysosomal compartment as intracellular calcium store in MDCK cells: a possible involvement in $\mathrm{InsP}^{3}$-mediated $\mathrm{Ca}^{2+}$ release. Cell Calcium 19: 157-165. 
10. Huо, L.; K. Yue; Z. Yang. 2002. Assessment of sperm viability mitochondrial activity, capacitation and acrosome intactness in extended boar semen during long-term storage. Theriogenology 58: 1349-1360.

11. Kao, S.; H. Chao; Y. Wei. 1998. Multiple deletions of mitochondrial DNA are associated with the decline of motility and fertility of human spermatozoa. Mol. Hum. Reprod. 4: 657-666.

12. Leyton, L.; A. De Iones; H. Croxatto; E. Graham; J. Elce. 1986. Two satisfactory methods for purification of human acrosin. Bioch. Cell Biol. 64: 1020-1024.

13. Linde-Forsberg, C. 1995. Artificial insemination with fresh, chilled extended and frozen-thawed semen in the dog. Semin. Vet. Med. Surg. 10: 48-58.

14. Linde-Forsberg, C. 2001. Intra-uterine insemination in the dog using the Scandinavian trans-cervical catheter and a comparison with other methods. Recent Advances in Small Animal Reproduction. Concannon, P.W.; G. England; J. Verstegen III; C. LindeForsberg (eds.) Ithaca, USA. En: International Veterinary Information Service (www.ivis.org); A1207.0201.

15. Linde-Forsberg, C.; M. Forsberg. 1989. Fertility in dogs in relation to semen quality and the time and site of insemination with fresh and frozen semen. J. Reprod. Fertil. Suppl. 39: 229.

16. Maxwell, W.; L. Johnson. 1999. Physiology of spermatozoa at high dilution rates: the influence of seminal plasma. Theriogenology 52: 1353-1362.

17. Moreno, R.; C. Barros. 2000. A basic 18 -amino acid peptide contain the polysulfate-binding domail responsable for activation of the boar proacrosin/ acrosin system. Biol. Reprod. 62: 15361542.

18. Moreno, R.; J. Ramalho-Santos; E. Chan; G. Wessel; G. Schatten. 2000. The Golgi apparatus segregates from the lysosomal acrosomal vesicle during
Rhesus spermatogenesis: structural alterations. Dev. Biol. 219: 334-349.

19. Moreno, R.; M. Sepúlveda; A. De Iones; C. Barros. 1998. The polysulphate binding domain of human proacrosin/acrosin is involved in both the enzyme activation and spermatozoa-zone pellucid interaction. Zygote 6: 75-83.

20. Parrish, J.; M. Susko-Parrish; A. Winer; L. First. 1988. Capacitation of bovine sperm by heparin. Biol. Reprod. 38: 1171-1180.

21. Peña, A.; C. Linde-Forsberg. 2000. Effect of spermatozoal concentration and post-thaw dilution rate on survival after thawing of dog spermatozoa. Theriogenology 54: 703-718.

22. Petrunkina, A., K. Simon; A. GunzelApel; E. Topfer-Petersen. 2003. Specific order in the appearance of protein tyrosine phosphorylation patterns is functionally coordinated with dog sperm hyperactivation and capacitation. J. Androl. 24: 423-437.

23. Ríos, M.; C. Barros. 1997. Trypsin-like enzymes during fertilization in the shrimp Rhynchocinetes typus. Mol. Reprod. Dev. 46: 581-586.

24. Rota, A.; A. Peña; C. Linde-Forsberg; H. Rodríguez-Martínez. 1999. In vitro capacitation of fresh, chilled, and frozenthawed dog spermatozoa assessed by the chloretetracycline assay and change in motility patterns. Anim. Reprod. Sci. 57: 199-215.

25. Rota, A.; B. Ström; C. Linde-Forsberg. 1995. Effect of seminal plasma and three extenders on canine semen stored at $4{ }^{\circ} \mathrm{C}$. Theriogenology 44: 885-900.

26. Sirivaidyapong, S.; F. Cheng; A. Marks; W. Voorhout; M. Bevers; B. Colenbrander. 2000. Effect of sperm diluents on the acrosome reaction in canine sperm. Theriogenology 53: 789802.

27. Sousa, M.; P. Moradas-Ferreira; $C$. Azevedo. 1992. Presence of a trypsinlike protease in starfish sperm acrosome. J. Exp. Zool. 261: 349-354. 
28. Sun, X.; M. MacFarlane; J. Zhuang; B. Wolf; D. Green; G. Cohen. 1999. Distinct caspase cascades are initiated in receptors-mediated and chemicalinduced apoptosis. J. Biol. Chem. 274: 5053-5060.

29. Thomas, C.; D. Garner; J. Dejarnette; C. Marshall. 1997. Fluorometric assessments of acrosomal integrity and viability in cryopreserved bovine spermatozoa. Biol. Reprod. 56: 991-998.

30. Thundathil, J.; J. Palomino; A. Barth; R. Mapletot; C. Barros. 2001. Fertilizing characteristics of bovine sperm with flattened or indented acrosomes. Anim. Reprod. Sci. 67: 231-243.

31. Tollner, T.; A. Yudin; G. Cherr; J. Overstreet. 2000. Soybean trypsin inhibitor as a probe for the acrosome reaction in motile cynomolgus macaque sperm. Zigote 8: 127-137.
32. Tsutsui, T.; T. Tezuka; Y. Mikasa; H. Sugisawa; N. Kirihara; T. Hori; E.

Kawakami. 2003. Artificial insemination with canine semen stored at a low temperature. J. Vet. Med. Sci. 65: 307-312.

33. Vetter, C.; J. Miller; L. Crawford; M. Armstrong; J. Clair; M. Conner; D. Wise; T. Skopel. 1998. Comparison of motility and membrane integrity to assess rat sperm viability. Reprod. Toxicol. 12: 105-114.

34. Watson, P.F. 1995. Recent developments and concepts in the cryopreservation of spermatozoa and the assessment of their post-thawing function. Reprod. Fertil. Dev. 7: 871-91.

35. Wheeler, M.; G. Seidel. 1987. Zona pellucida penentration assay for capacitation of bovine sperm. Gam. Res. 18: 237-250. 